\title{
Mass Stopping Power and Range of Protons in Biological Human Body Tissues (Ovary, Lung and Breast)
}

\author{
Ahlam S. Almutairi', Khalda T. Osman ${ }^{2 *}$ \\ ${ }^{1}$ Department of Physics, College of Science, Qassim University, AL-Rass, Saudi Arabia \\ ${ }^{2}$ Department of Physics, College of Science, Qassim University, Buraydah, Saudi Arabia \\ Email: *khaldateosman@gmail.com
}

How to cite this paper: Almutairi, A.S. and Osman, K.T. (2022) Mass Stopping Power and Range of Protons in Biological Human Body Tissues (Ovary, Lung and Breast). International Journal of Medical Physics, Clinical Engineering and Radiation Oncology, 11, 4859.

https://doi.org/10.4236/ijmpcero.2022.111005

Received: January 24, 2022

Accepted: February 13, 2022

Published: February 16, 2022

Copyright $\odot 2022$ by author(s) and Scientific Research Publishing Inc. This work is licensed under the Creative Commons Attribution International License (CC BY 4.0).

http://creativecommons.org/licenses/by/4.0/

\section{(c) (i) Open Access}

\section{Abstract \\ In this work, the mass stopping power and range of protons in biological human body tissues (ovary, lung and breast) were calculated at the energy ranging from $0.04 \mathrm{MeV}$ to $200 \mathrm{MeV}$ using the MATLAB Program. The data relating to the densities, average atomic number to mass number $\left\langle\frac{Z}{A}\right\rangle$ and} excitation energy for the present tissues were collected from ICRU Report 46. The mass stopping power was calculated by the Bethe formula. Moreover, the simple integration (continuous slowing down approximation) method was employed for calculating protons range at the tissues. The results of the mass stopping power versus energy and the range versus energy were presented graphically and the empirical formulae for calculating the mass stopping power and the ranges were obtained. The present results for mass stopping powers and ranges were compared with the results obtained by others. Good agreements were found between them, especially at the energy ranging from 3 to 200 $\mathrm{MeV}$.

\section{Keywords}

Human Body Tissues, Protons, Range, MATLAB, Mass Stopping Power

\section{Introduction}

The stopping power and energy dissipation of charged particles through matter has been a subject of great interest for 100 years, because of its wide areas of application, such as ion implantation, fundamental particle physics, nuclear physics, radiation damage, radiology [1]. 
In recent years, the theoretical and experimental studies of the Stopping Power (SP) and range of charged particles have been increasing, especially in radiation physics. Many theoretical, as well as experimental studies have been established on this topic quite efficiently [2]. In particular, the use of protons or heavier ions are increasing as an alternative to external photon beams in radiotherapy, the reason is attributed to preserving the target dose, ensuring a higher dose delivered to the tumor and being able to transfer energy in the form of point shot through the diseased tissue due to the Bragg curve [3].

Charged particles are often used for radiotherapy because they have a well-defined penetration in tissues, the depth is dependent on the incident energy of particles and the nature of the irradiated material. Charged particles (protons, deuterons, alpha particles) have an important effect in radiotherapy as they have the ability to deliver their energy to the target [4].

For protons, the main contribution to the total stopping power is provided by the electronic stopping power which is based on inelastic collisions with the target's electrons. Conversely, the least contributing to the total stopping power comes from nuclear stopping power which arises from elastic collisions with the target's nucleons and is only significant at very low energy. For instance, the nuclear stopping power conduces more than one percent to the total stopping power only at energy below $20 \mathrm{KeV}$ for protons [5]. Hence, precise knowledge of stopping power and range of protons are needed for the exact dosimetry of proton radiation. When studying the stopping power and range of protons in biological tissues, one must determine or collect data from experimentally or ICRU reports.

Heavy charged particles traversing matter lose energy primarily through the ionization and excitation of atoms. The stopping power is defined as the mean energy loss per unit path length $-\mathrm{d} E / \mathrm{d} x$. It depends on the charge and velocity of the projectile and, of course, the target material [6] [7].

Early investigation of the energy loss of charged particles traversing matter arrives at a general stopping power formula:

$$
-\frac{\mathrm{d} E}{\mathrm{~d} x}=\frac{4 \pi e^{4} N Z_{2}}{m_{e} v^{2}} Z_{1}^{2} B
$$

where: $N$ is the target density, $Z_{2}$ is the target atomic number, $m_{e}$ is the electron mass, $v$ and $Z_{1}$ are the projectile velocity and charge respectively and $B$ is called the "stopping number" [7].

The negative sign in Equation (1) signifies the fact that the particles lose energy as they pass through the material. For most practical purposes, the physics of the energy loss phenomena are complex, and will be not covered in detail [8].

If an ion beam penetrates through matter it loses energy due to collisions with electrons (electronic stopping) and target nuclei (nuclear stopping) [9].

Then, the total stopping power is just the sum of the stopping powers due to electronic and nuclear interactions. The nuclear component of the stopping power 
can also be ignored [10].

\section{Methods}

The first quantum mechanical study of stopping power was done by Bethe. Bethe theory of stopping is valid when the projectile's velocity is higher than the Bohr velocity. In Bethe theory, the target is assumed as an elemental material. Bethe's treatment of the energy loss is based on the born approximation applied to the inelastic collisions between the heavy particle and the atomic electrons. In this theory, the projectile heavy particle is assumed to be structure less, and the target nucleus is assumed infinitely massive [11].

\section{1) Calculations of electronic stopping power}

The following Bethe mass stopping power equation has been used for energy range $0.04-200 \mathrm{MeV}$ [12]:

$$
-\frac{\mathrm{d} E}{\rho \mathrm{d} x}=\frac{5.08 \times 10^{-31} z^{2} n}{\beta^{2} \rho}[F(\beta)-\ln I]
$$

where: $\beta$ is $v / c$ where $v$ is the proton velocity and $c$ is light velocity, $I$ is the mean excitation energy and $F(\beta)$ is given by:

$$
F(\beta)=\ln \frac{1.02 \times 10^{6} \beta^{2}}{1-\beta^{2}}-\beta^{2}
$$

$n$ is calculated using the following relation:

$$
n=N_{a v} \rho\left\langle\frac{Z}{A}\right\rangle
$$

where: $N_{a}$ is Avogadro number, $\rho$ is the density of substances and $Z / A$ is the ratio of atomic number to the mass number of substances. The basic data for human body tissues are given in Table 1. The calculated mass stopping power of protons for lung, breast and ovary are based on Bethe equation after substituting the constants from Table 1. In Table 2, the compositions of the human tissues are given.

\section{2) Calculations of range}

Range, $R$ the range for a heavy particle is the straight distance traveled by the particle within the target. Light particles like electrons, positrons can be scattered in the path of the targets with large angles due to their low weight and it is difficult to calculate their path length. Monte Carlo methods that are based on a broad class of computational algorithms have been used in a successful manner specially for calculating the path length of light particles. On the other hand, the path length of heavy particles like protons is almost straight line. The range of protons can be calculated by some numerical integration methods. But the Continuous Slowing Down Approximation (CSDA) is a simple and common method to calculate the range of the heavy particles like protons in the targets and this method is employed in this study. Incident particles continuously lose their energy in the path of the targets and the CSDA method neglects energy loss fluctuations. 
Table 1. Basic Data for calculating mass stopping powers.

\begin{tabular}{ccccc}
\hline Substances & Density $\rho\left(\mathrm{g} / \mathrm{m}^{3}\right)$ & $\langle\mathrm{Z} / \mathrm{A}\rangle$ & $n\left(\right.$ electrons $\left./ \mathrm{m}^{3}\right)$ & $I(\mathrm{eV})$ \\
\hline Lung & 1050,000 & 0.550 & $3.476 \times 10^{29}$ & 75.2 \\
Breast & 1020,000 & 0.551 & $3.383 \times 10^{29}$ & 70.3 \\
Ovary & 1050,000 & 0.551 & $3.482 \times 10^{29}$ & 75 \\
\hline
\end{tabular}

Table 2. Elemental composition of Lung, Breast and Ovary tissues.

\begin{tabular}{cc}
\hline Substances & \multicolumn{1}{c}{ Composition } \\
\hline \multirow{2}{*}{ Lung } & $\mathrm{C}(0.105000), \mathrm{N}(0.031000), \mathrm{H}(0.103000), \mathrm{O}(0.749000)$, \\
& $\mathrm{Na}(0.002000), \mathrm{P}(0.002000), \mathrm{S}(0.003000)$ \\
\multirow{2}{*}{ Breast } & $\mathrm{C}(0.332000), \mathrm{N}(0.030000), \mathrm{H}(0.106000), \mathrm{O}(0.527000)$, \\
& $\mathrm{Na}(0.001000), \mathrm{P}(0.001000), \mathrm{S}(0.002000), \mathrm{Cl}(0.001000)$ \\
\multirow{2}{*}{ Ovary } & $\mathrm{C}(0.093000), \mathrm{N}(0.024000), \mathrm{H}(0.105000), \mathrm{O}(0.768000)$, \\
& $\mathrm{Na}(0.002000), \mathrm{P}(0.002000), \mathrm{S}(0.002000), \mathrm{Cl}(0.002000), \mathrm{K}(0.002000)$ \\
\hline
\end{tabular}

The range, $\mathrm{R}$ for an incident proton in the CSDA method is given as:

$$
R=\int_{E_{0}}^{E_{f}} \frac{\mathrm{d} E}{M S(E)}
$$

where: $E_{0}$ is the initial energy of incident charged particle in material, $E_{f}$ is the final energy of incident charged particle in material and $M S(E)$ is the mass stopping power [1].

\section{Results and Discussion}

The results of mass stopping powers for the present tissues are given in Table 3. In Figures 1-3, the mass stopping power of tissues and their compositions are plotted and it is noted that the mass stopping power of all tissues represent the average values of its compositions. The comparison between the present calculated mass stopping powers and that of Ref. [5] are shown in Figures 4-6, and good agreements between two results are observed in energy range $3-200 \mathrm{MeV}$.

In Table 4, the ranges of all present human tissues are given. In Figures 7-9, a comparison between present results of ranges in all tissues and that of Ref. [5] are shown in energy range $0.04-200 \mathrm{MeV}$ and good agreements are observed. In Table 5 and Table 6 the empirical formulae for calculating mass stopping powers and ranges for all present human tissues are given. Also percentage difference between the present results of mass stopping powers and ranges and that of Ref. [5] are calculated for all tissues and the range of differences of percentage errors are given in Table 7 .

\section{Conclusion}

In this work, calculations of mass stopping power and range of protons incident on the three different human body tissues (lung, breast and ovary) have been 
Table 3. Values of mass stopping power (in $\mathrm{MeV} \mathrm{cm}^{2} / \mathrm{g}$ ) of lung, breast and ovary tissues.

\begin{tabular}{|c|c|c|c|}
\hline \multirow[t]{2}{*}{ Proton energy ( $\mathrm{MeV}$} & \multicolumn{3}{|c|}{ Mass stopping power (in $\mathrm{MeV} \mathrm{cm}^{2} / \mathrm{g}$ ) } \\
\hline & Lung & Breast & Ovary \\
\hline 0.04 & 282.2618 & 417.5179 & 288.6849 \\
\hline 0.06 & 722.7380 & 813.8908 & 727.9282 \\
\hline 0.08 & 826.5003 & 895.3875 & 830.8763 \\
\hline 0.1 & 837.7000 & 893.1341 & 841.5006 \\
\hline 0.2 & 692.9473 & 721.1679 & 695.3133 \\
\hline 0.4 & 483.4803 & 497.8423 & 484.8960 \\
\hline 0.6 & 375.7261 & 358.3989 & 376.7606 \\
\hline 0.8 & 310.2014 & 317.5082 & 311.0256 \\
\hline 1.0 & 265.7808 & 271.6586 & 266.4701 \\
\hline 2.0 & 160.2245 & 163.2136 & 160.6155 \\
\hline 4.0 & 93.7372 & 95.2568 & 93.9559 \\
\hline 6.0 & 67.7816 & 68.8044 & 67.9364 \\
\hline 8.0 & 53.6391 & 54.4113 & 53.7599 \\
\hline 10.0 & 44.6429 & 45.2639 & 44.7426 \\
\hline 20.0 & 24.9792 & 25.2946 & 25.0335 \\
\hline 30.0 & 17.6660 & 17.8781 & 17.7039 \\
\hline 40.0 & 13.7764 & 13.9365 & 13.8058 \\
\hline 50.0 & 11.3406 & 11.4692 & 11.3646 \\
\hline 60.0 & 9.6628 & 9.7704 & 9.6832 \\
\hline 70.0 & 8.4326 & 8.5251 & 8.4504 \\
\hline 80.0 & 7.4896 & 7.5707 & 7.5053 \\
\hline 90.0 & 6.7423 & 6.8145 & 6.7563 \\
\hline 100.0 & 6.1346 & 6.1997 & 6.1474 \\
\hline 110.0 & 5.6301 & 5.6895 & 5.6419 \\
\hline 120.0 & 5.2043 & 5.2588 & 5.2151 \\
\hline 130.0 & 4.8397 & 4.8901 & 4.8498 \\
\hline 140.0 & 4.5239 & 4.5707 & 4.5333 \\
\hline 150.0 & 4.2475 & 4.2912 & 4.2563 \\
\hline 160.0 & 4.0034 & 4.0445 & 4.0117 \\
\hline 170.0 & 3.7863 & 3.8249 & 3.7941 \\
\hline 180.0 & 3.5917 & 3.6282 & 3.5991 \\
\hline 190.0 & 3.4163 & 3.4510 & 3.4234 \\
\hline 200.0 & 3.2574 & 3.2903 & 3.2641 \\
\hline
\end{tabular}




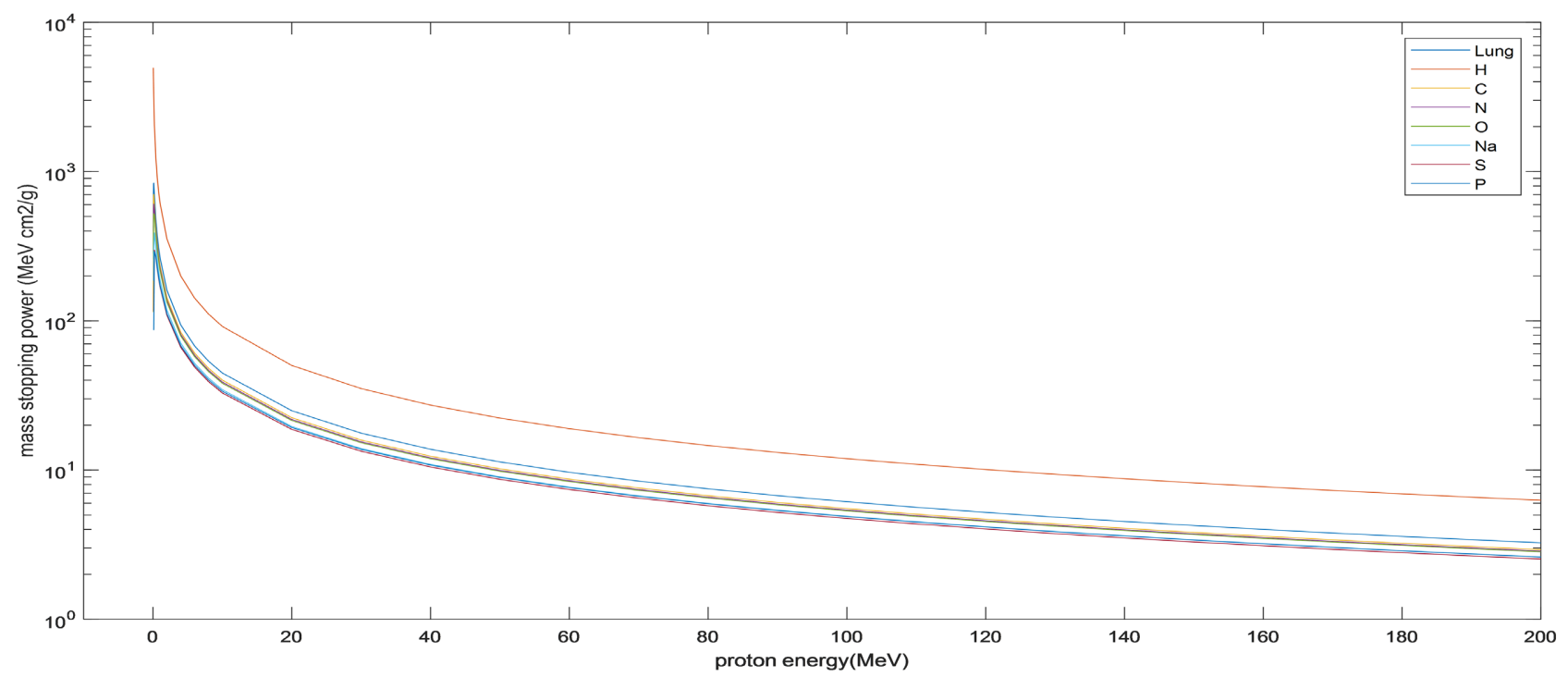

Figure 1. Mass stopping power of Lung and its composition.

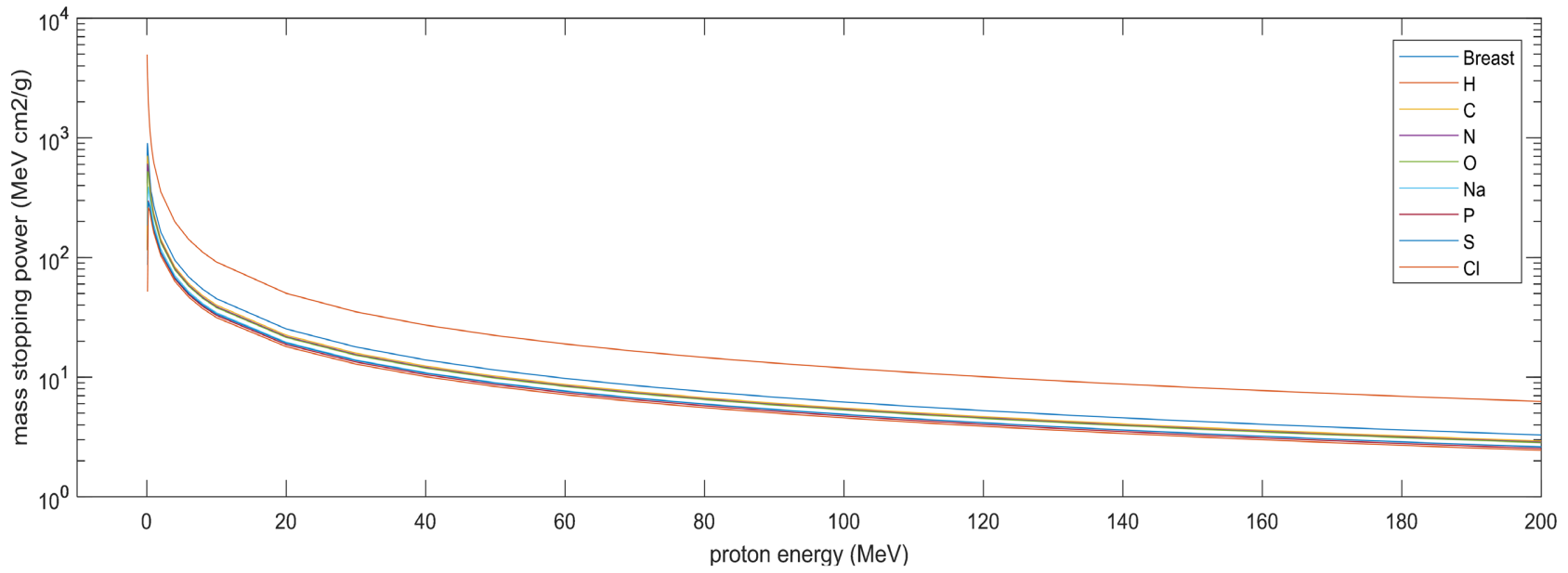

Figure 2. Mass stopping power of Breast and its composition.

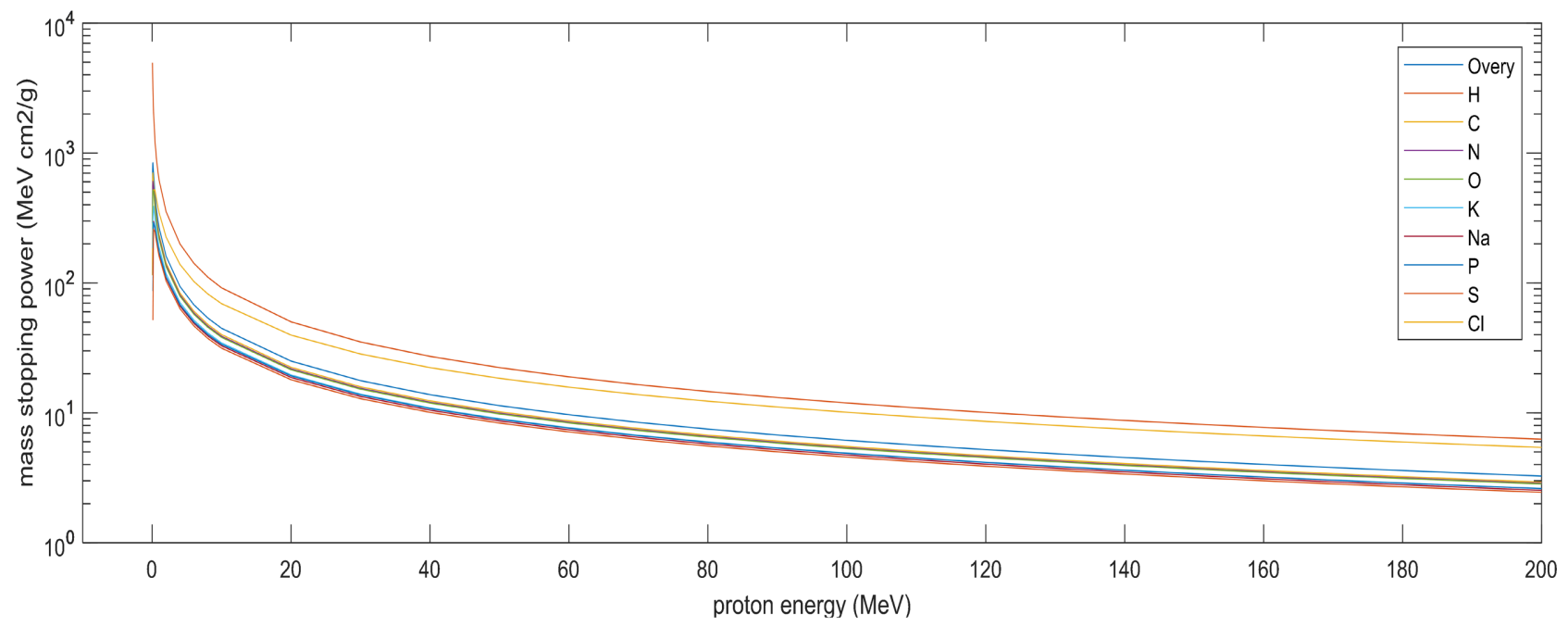

Figure 3. Mass stopping power of ovary and its composition. 


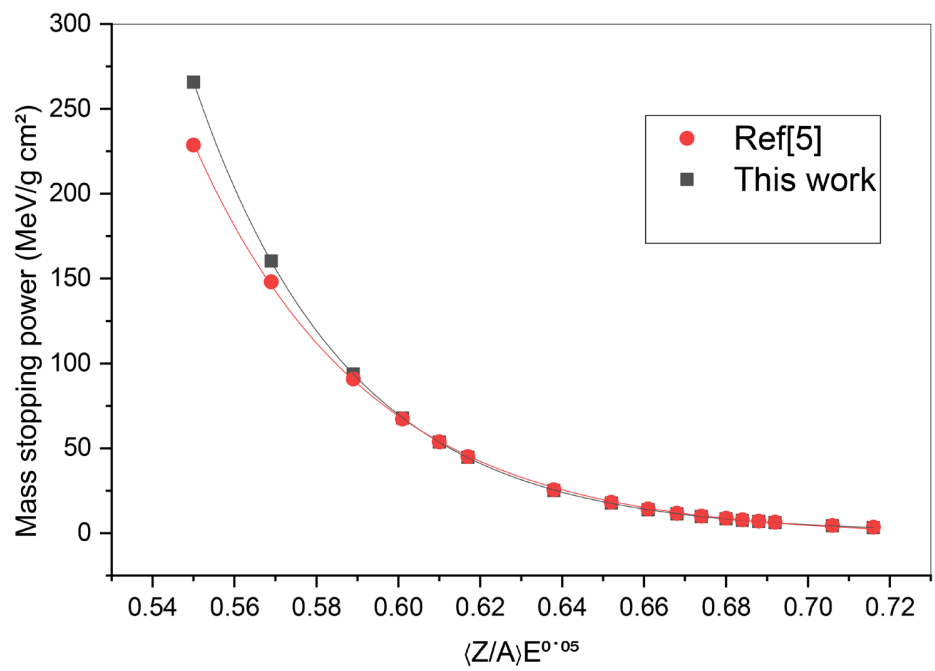

Figure 4. Mass stopping power of Lung versus $\left\langle\frac{Z}{A}\right\rangle E^{0.05}$.

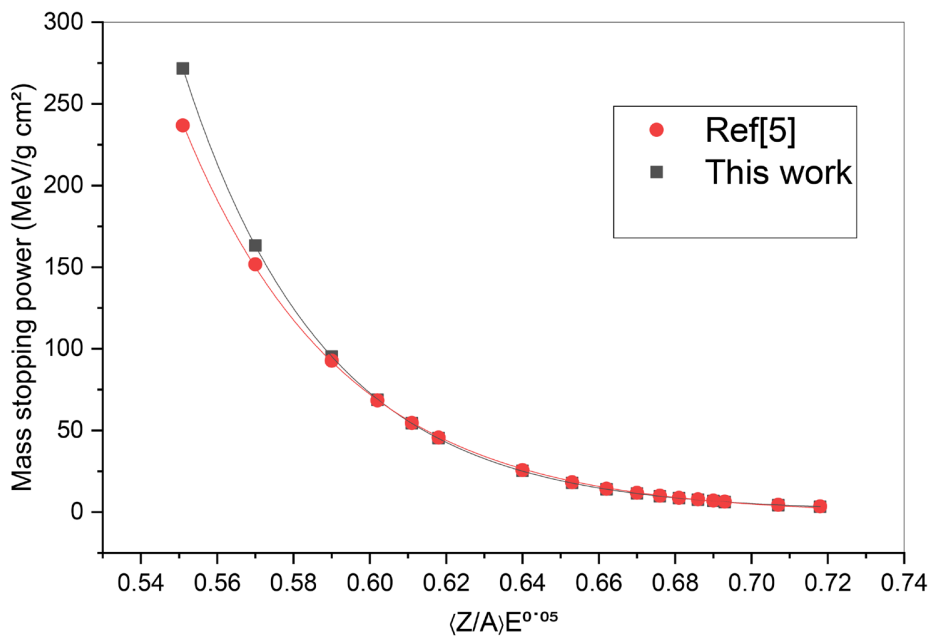

Figure 5. Mass stopping power of Breast versus $\left\langle\frac{Z}{A}\right\rangle E^{0.05}$.

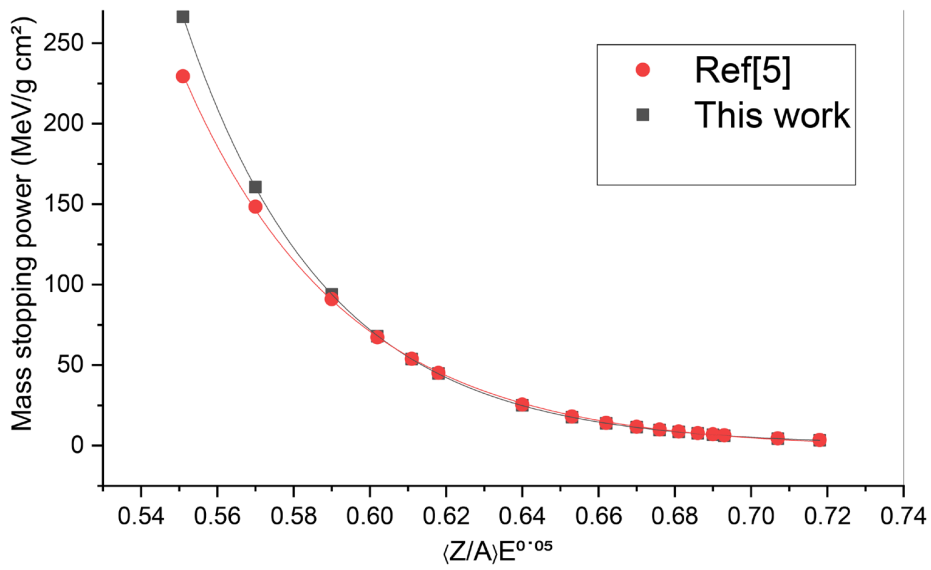

Figure 6. Mass stopping power of Overy versus $\left\langle\frac{Z}{A}\right\rangle E^{0.05}$. 
Table 4. Values of range (in $\mathrm{g} / \mathrm{cm}^{2}$ ) of lung, breast and ovary.

\begin{tabular}{|c|c|c|c|}
\hline \multirow{2}{*}{ Proton energy $(\mathrm{MeV})$} & \multicolumn{3}{|c|}{ Range $\left(\mathrm{g} / \mathrm{cm}^{2}\right)$} \\
\hline & Lung & Breast & Ovary \\
\hline 0.04 & $1.512 \times 10^{-5}$ & $1.345 \times 10^{-5}$ & $1.499 \times 10^{-5}$ \\
\hline 0.06 & $3.008 \times 10^{-5}$ & $2.692 \times 10^{-5}$ & $2.983 \times 10^{-5}$ \\
\hline 0.08 & $4.900 \times 10^{-5}$ & $4.403 \times 10^{-5}$ & $4.860 \times 10^{-5}$ \\
\hline 0.1 & $7.154 \times 10^{-5}$ & $6.449 \times 10^{-5}$ & $7.098 \times 10^{-5}$ \\
\hline 0.2 & $2.318 \times 10^{-4}$ & $2.109 \times 10^{-4}$ & $2.301 \times 10^{-4}$ \\
\hline 0.4 & $7.510 \times 10^{-4}$ & $6.902 \times 10^{-4}$ & $7.462 \times 10^{-4}$ \\
\hline 0.6 & 0.0015 & 0.0014 & 0.0015 \\
\hline 0.8 & 0.0024 & 0.0023 & 0.0024 \\
\hline 1.0 & 0.0036 & 0.0033 & 0.0035 \\
\hline 2.0 & 0.0115 & 0.0108 & 0.0115 \\
\hline 4.0 & 0.0373 & 0.035 & 0.0371 \\
\hline 6.0 & 0.0742 & 0.070 & 0.0739 \\
\hline 8.0 & 0.120 & 0.115 & 0.120 \\
\hline 10.0 & 0.176 & 0.169 & 0.175 \\
\hline 20.0 & 0.571 & 0.555 & 0.570 \\
\hline 30.0 & 1.137 & 1.110 & 1.134 \\
\hline 40.0 & 1.852 & 1.815 & 1.848 \\
\hline 50.0 & 2.704 & 2.659 & 2.699 \\
\hline 60.0 & 3.684 & 3.631 & 3.678 \\
\hline 70.0 & 4.784 & 4.727 & 4.778 \\
\hline 80.0 & 6.001 & 5.939 & 5.994 \\
\hline 90.0 & 7.327 & 7.265 & 7.320 \\
\hline 100.0 & 8.761 & 8.699 & 8.753 \\
\hline 110.0 & 10.298 & 10.239 & 10.290 \\
\hline 120.0 & 11.936 & 11.882 & 11.927 \\
\hline 130.0 & 13.671 & 13.625 & 13.662 \\
\hline 140.0 & 15.502 & 15.465 & 15.493 \\
\hline 150.0 & 17.427 & 17.402 & 17.418 \\
\hline 160.0 & 19.442 & 19.433 & 19.434 \\
\hline 170.0 & 21.548 & 21.555 & 21.540 \\
\hline 180.0 & 23.741 & 23.769 & 23.734 \\
\hline 190.0 & 26.021 & 26.071 & 26.014 \\
\hline 200.0 & 28.386 & 28.461 & 28.380 \\
\hline
\end{tabular}




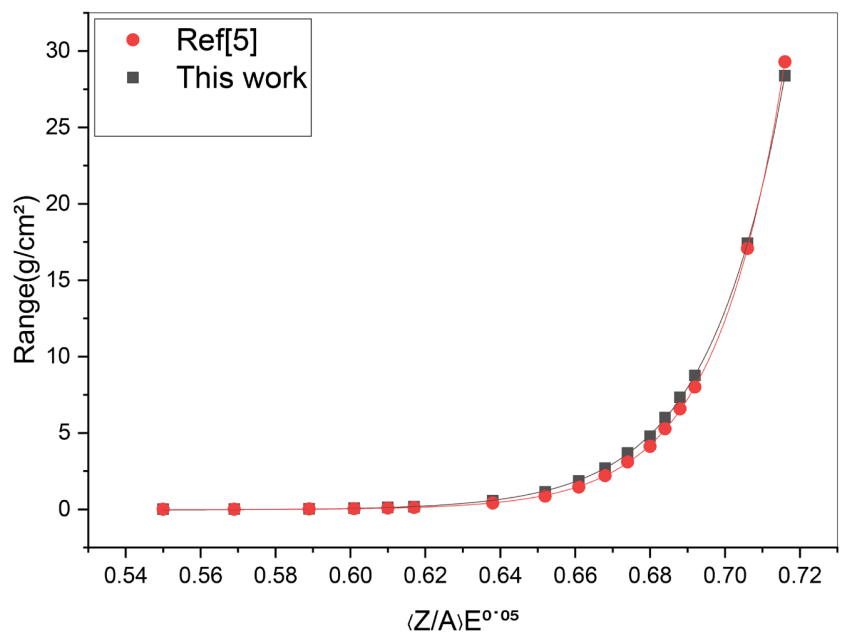

Figure 7. Range of Lung versus $\left\langle\frac{Z}{A}\right\rangle E^{0.05}$.

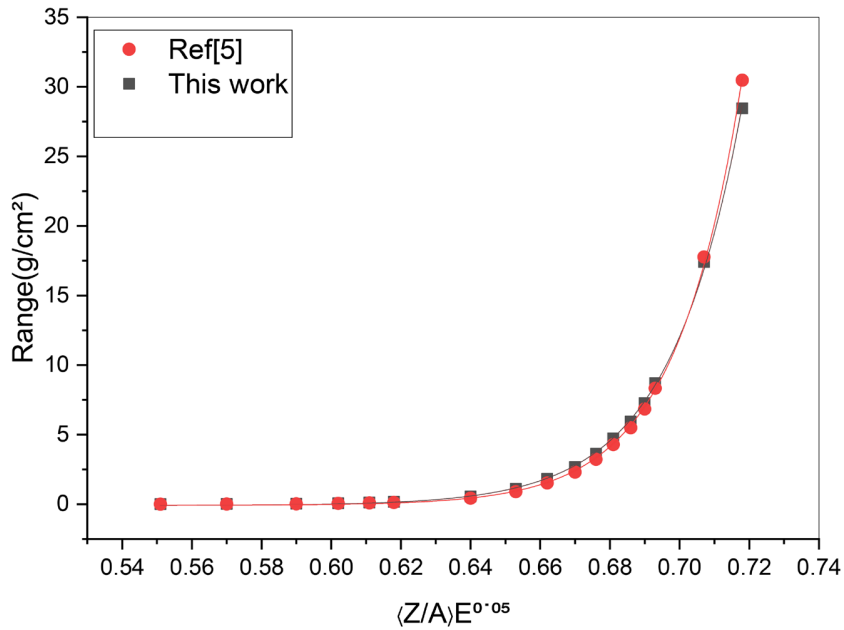

Figure 8. Range of Breast versus $\left\langle\frac{Z}{A}\right\rangle E^{0.05}$.

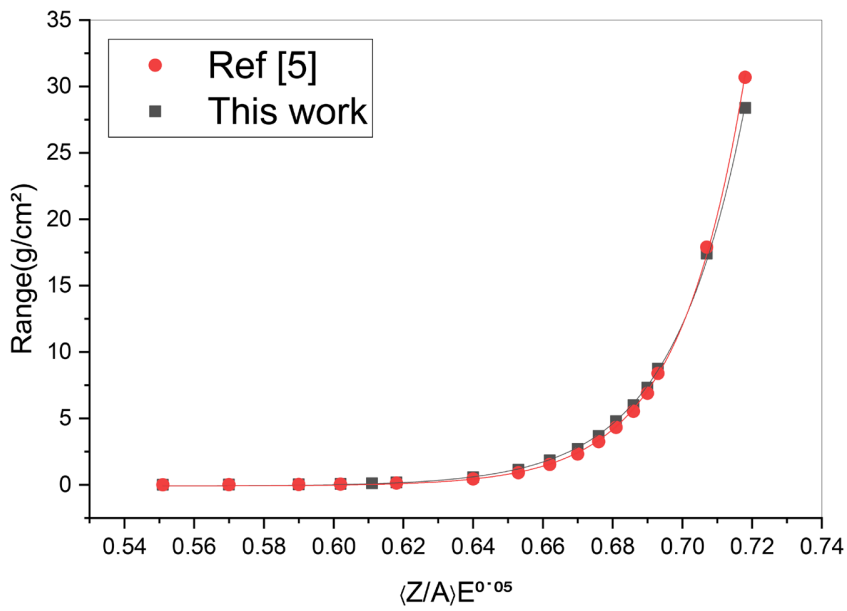

Figure 9. Range of Ovary versus $\left\langle\frac{Z}{A}\right\rangle E^{0.05}$. 
Table 5. The empirical formulae for calculating mass stopping powers.

\begin{tabular}{ccc}
\hline \multirow{2}{*}{ Substances } & \multicolumn{2}{c}{ The empirical formulae for calculating mass stopping powers } \\
\cline { 2 - 3 } & \multicolumn{2}{c}{$y=A_{1} \mathrm{e}^{x / t_{1}}+y_{o}$} \\
\cline { 2 - 3 } This work & Ref. [5] \\
& $A_{1}=6.4723 \times 10^{8}, t_{1}=-0.0374$ & $A_{1}=1.0140 \times 10^{8}, t_{1}=-0.04235$ \\
& $y_{o}=0.10311$ & $y_{o}=-2.17377$ \\
Breast & $R^{2}=0.99999$ & $R^{2}=0.99982$ \\
& $A_{1}=7.424 \times 10^{8}, t_{1}=-0.03717$ & $A_{1}=1.3298 \times 10^{8}, t_{1}=-0.04166$ \\
& $y_{o}=0.33231$ & $y_{0}=-1.74685$ \\
Ovary & $R^{2}=0.99999$ & $R^{2}=0.99988$ \\
& $A_{1}=6.7234 \times 10^{8}, t_{1}=-0.0374$ & $A_{1}=1.05463 \times 10^{8}, t_{1}=-0.0423$ \\
& $y_{0}=0.25388$ & $y_{o}=-1.998$ \\
$R^{2}=1$ & $R^{2}=0.99984$ \\
\hline
\end{tabular}

Table 6. The empirical formulae for calculating range.

\begin{tabular}{ccc}
\hline \multirow{2}{*}{ Substances } & \multicolumn{2}{c}{ The empirical formulae for calculating range } \\
\cline { 2 - 3 } & \multicolumn{2}{c}{$y=A_{1} \mathrm{e}^{x / t_{1}}+y_{o}$} \\
\cline { 2 - 3 } This work & Ref. [5] \\
\hline \multirow{2}{*}{ Lung } & $A_{1}=2.0524 \times 10^{-14}, t_{1}=0.02054$ & $A_{1}=5.6893 \times 10^{-16}, t_{1}=0.01861$ \\
& $y_{o}=-0.04347$ & $y_{o}=-0.0191$ \\
Breast & $R^{2}=0.99999$ & $R^{2}=0.99992$ \\
& $A_{1}=3.1976 \times 10^{-14}, t_{1}=0.02058$ & $A_{1}=1.5038 \times 10^{-15}, t_{1}=0.01912$ \\
Ovary & $y_{o}=-0.09494$ & $y_{o}=-0.08055$ \\
& $R^{2}=1$ & $R^{2}=0.99988$ \\
& $A_{1}=4.1072 \times 10^{-14}, t_{1}=0.02102$ & $A_{1}=1.5704 \times 10^{-15}, t_{1}=0.01914$ \\
& $y_{o}=-0.09538$ & $y_{o}=-0.08739$ \\
$R^{2}=1$ & $R^{2}=0.99984$
\end{tabular}

Table 7. Percentage difference between present result and that of Ref. [5].

\begin{tabular}{ccc}
\hline Tissue & $\begin{array}{c}\text { Range of percentage difference } \\
\text { between present result and Ref. [5] of } \\
\text { mass stopping power }\end{array}$ & $\begin{array}{c}\text { Range of percentage difference } \\
\text { between present result and Ref. [5] } \\
\text { of range }\end{array}$ \\
\hline Breast & $-6.07 \%-12.82 \%$ & $-7.06 \%-21.29 \%$ \\
Lung & $-6.46 \%-13.95 \%$ & $-3.20 \%-26.95 \%$ \\
Ovary & $-6.44 \%-13.91 \%$ & $-8.13 \%-23.47 \%$ \\
\hline
\end{tabular}

done and the following conclusions are drawn:

1) The mass stopping power of each tissue gives the average value of mass stopping power of its compositions in energy range of $0.04-200 \mathrm{MeV}$;

2) It is also noted that the empirical formulae for both mass stopping power and range for each human tissue studied in the present work are simple and widely applicable; 
3) Values for mass stopping power and ranges of protons for breast, lung and ovary tissues are in good agreement with the data proposed by other researchers. This comparison is very important in terms of reliability of present work;

4) It also observed that the maximum value of mass stopping power was at 0.1 $\mathrm{MeV}$ and after that, the mass stopping power started to decrease with increasing energy;

5) The empirical formulae suggested for mass stopping power and ranges of protons are simple and they covered a large range of proton energy ( $1-200 \mathrm{MeV})$ as well as gave important information for those interesting in proton therapy.

\section{Acknowledgements}

The authors thank the Department of Physics, Qassim University, for its support and encouragement of this research.

\section{Conflicts of Interest}

The authors declare no conflicts of interest regarding the publication of this paper.

\section{References}

[1] Tufan, M.C. and Gümüs, H. (2008) Stopping Power Calculations of Compounds by Using Thomas-Fermi-Dirac-Weizsäcker Density Functional. Acta Physica Polonica $A, 114,703-711$. https://doi.org/10.12693/APhysPolA.114.703

[2] Ahmed, I., Nowrin, H. and Dhar, H. (2020) Stopping Power and Range Calculations of Protons in Human Tissues. Baghdad Science Journal, 17, Article No. 1223. https://doi.org/10.21123/bsj.2020.17.4.1223

[3] Usta, M., Tufan, M.Ç., Aydın, G. and Bozkurt, A. (2018) Stopping Power and Dose Calculations with Analytical and Monte Carlo Methods for Protons and Prompt Gamma Range Verification. Nuclear Instruments and Methods in Physics Research Section A: Accelerators, Spectrometers, Detectors and Associated Equipment, 897, 106-113. https://doi.org/10.1016/j.nima.2018.04.045

[4] Sarsam, M.N. (2013) Theoretical Study of Energy Loss of Proton in Human Tissues. Al-Qadisiyah Journal of Pure Science, 18, 23-31. https://www.iasj.net/iasj/article/94610

[5] Usta, M. and Tufan, M.Ç. (2017) Stopping Power and Range Calculations in Human Tissues by Using the Hartree-Fock-Roothaan Wave Functions. Radiation Physics and Chemistry, 140, 43-50. https://doi.org/10.1016/j.radphyschem.2017.03.005

[6] Tai, H., Bichsel, H., Wilson, J.W., Shinn, J.L., Cucinotta, F.A. and Badavi, F.F. (1997) Comparison of Stopping Power and Range Databases for Radiation Transport Study. NASA Technical Paper 3644.

https://www.researchgate.net/profile/Hans-Bichsel/publication/2506344 Comparison o f Stopping_Power and Range Databases for Radiation Transport Study/links/0912f 50e4611af259f000000/Comparison-of-Stopping-Power-and-Range-Databases-for-Radia tion-Transport-Study.pdf

[7] Csete, A. (2002) Experimental Investigations of the Energy Loss of Slow Protons and Antiprotons in Matter. Doctoral Dissertation, University of Aarhus. https://s3.cern.ch/inspire-prod-files-0/0b76b3fbee61933a702dd6ca2592e95a

[8] Ahmed, S.N. (2007) Physics and Engineering of Radiation Detection. Academic Press.

[9] Mayer, M. (2003, May). Rutherford Backscattering Spectrometry (RBS). In Workshop 
on Nuclear Data for Science and Technology: Materials Analysis, Vol. 34.

https://scholar.google.com/scholar?hl=en\&as sdt=0\%2C5\&q=Mayer\%2C+M.+\%2820 03\%2C+May\%29.+Rutherford+backscattering+spectrometry+\%28RBS\%29.+In+Wor kshop+on+Nuclear+Data+for+Science+and+Technology $\% 3 \mathrm{~A}+$ Materials + Analysis $+\% 28 \mathrm{Vol} .+34 \% 29.8 \mathrm{btnG}$

[10] Peltola, J. (2003) Stopping Power for Ions and Clusters in Crystalline Solids. https://helda.helsinki.fi/bitstream/handle/10138/23266/stopping.pdf?sequence $=2$

[11] Jassim, W.N. (2015) Study of Proton Stopping Power in Be, C, Al and Cu with Energy (1-12) MeV. International Journal of Science and Research, 4, 874-877.

https://www.researchgate.net/profile/Wafaa-Nsyif/publication/327974897 Study of Pro ton Stopping Power in $\mathrm{Be} \mathrm{C} \mathrm{Al}$ and $\mathrm{Cu}$ with Energy $1-12 \mathrm{MeV} /$ links/5bb0f6cca6f $\underline{\mathrm{dccd} 3 \mathrm{cb}}$

[12] Osman, K.T. (2020) Stopping Powers of Protons in Biological Human Body Substances (Water, Tissue, Muscles and Bones). International Journal of Novel Research in Physics Chemistry \& Mathematics, 7, 8-12.

https://www.noveltyjournals.com/upload/paper/Stopping\%20Powers\%20of\%20Prot ons-2236.pdf 